\title{
llustración, independencia e instrucción pública en Chiapas. Fray Matías de Córdova, 1766-1828 ${ }^{1}$
}

Enlightenment, Independence and Public Instruction in Chiapas: Fr. Matías de Córdova, 1766-1828

\section{Rosalina Ríos Zúñiga}

Instituto de Investigaciones Sobre la Universidad y la Educación, UNAM

melian8@icloud.com

\section{Resumen}

\begin{abstract}
Este artículo analiza algunos de los aportes educativos de fray Matías de Córdova a la instrucción pública en Chiapas, porque busca explicar los rasgos ilustrados e independentistas que los caracterizaban. Con ese fin, se aborda la biografía del fraile dominico, haciendo énfasis en el carácter ilustrado de su educación, así como su participación en los procesos de emancipación tanto de su provincia eclesiástica, como de su estado; se examina la situación de la educación de primeras letras en Chiapas, los aportes de Córdova para mejorarla y su colaboración en otros proyectos como el de la Universidad Literaria y la Normal, entre otros. Los materiales que han hecho posible este trabajo proceden del Archivo Histórico de Centroamérica, del Archivo Histórico Diocesano de Chiapas, así como del Museo del Libro y de la Hemeroteca Nacional, ambos de Guatemala, además de la historiografía sobre el tema.
\end{abstract}

Palabras clave: fray Matías de Córdova, Chiapas, instrucción pública, siglo XIX, métodos de enseñanza.

\section{Abstract}

This article analizes the public education plans of Fr. Matias de Córdova in Chiapas, seeking to identify their illustrated and independentist character, and trying to find out the way in which this character had an impact on their application. In order to achive that aim, the article, based on sources from differents archives and historiography on the topic, explores the biography of Matías de Córdova, his participation in the process of Chiapas' clerical and political emancipation, analizes

\footnotetext{
${ }^{1}$ Mi agradecimiento a los dictaminadores del presente texto porque su minuciosa revisión me hizo repensar el problema planteado así como mejorarlo en todos sus aspectos. Como suele suceder, sin embargo, todo lo que se dice es de mi entera responsabilidad.
} 
the condition of elementary schooling at the beginning of the nineteenth century in Chiapas, and finally explores the contribution of Córdova in the different levels of public education (university, teacher training and others).

Keywords: Fray Matías de Córdova, Chiapas, Public education, Nineteenth Century, Teaching Methods.

\section{Introducción}

Cuando fue declarada la independencia de Chiapas en 1821, fray Matías de Córdova, fraile dominico, hombre ilustrado y liberal de su tiempo, ya había intervenido en algunos proyectos ilustrados -era socio de la Sociedad Económica de Amigos de Guatemala, propuso cómo debían calzar y vestir los indígenas a la española y había comenzado a escribir un método para que los niños aprendieran más rápido a leer y escribir-, así como en actividades en pro de la separación de la provincia dominica chiapaneca de la mayor a la que estaba adscrita, con sede en Guatemala. ${ }^{2}$ En el caso de la educación pública, desde décadas atrás, uno de los intereses más importantes que se había manifestado por parte de las autoridades españolas era que se extendiera la enseñanza de las primeras letras a la mayoría de la población, sin embargo, diversas problemáticas características de la zona (como la geografía del lugar, la falta de conocimiento de los dialectos por parte de quienes debían encargarse de la enseñanza, así como la reticencia de los padres a enviar a sus hijos a la escuela —especialmente en el caso de quienes vivían en el campo-) habían impedido lograr mucho. De hecho, el problema del alto analfabetismo, especialmente entre la población indígena, sigue aún hoy sin resolverse (Camacho, 2018).

Los esfuerzos emprendidos por el dominico entre fines del siglo XVIII y primeras décadas del XIX, que se inscriben dentro de una larga serie de proyectos encaminados a castellanizar y alfabetizar a la población, fueron por eso importantes; estos afanes respondían al mismo ambiente que se respiraba durante el periodo en que vivió fray Matías, como fruto de la Ilustración, las reformas borbónicas, la Constitución de Cádiz y después la obtención de las independencias americanas. ${ }^{3}$ La reconstrución de la historia de la instrucción pública en

${ }^{2}$ La primera Orden que arribó a Chiapas fue la de los mercedarios en 1537; sin embargo, las labores de evangelización no fueron iniciadas por ellos sino por la Orden de Predicadores, quienes llegaron y se instalaron en Ciudad Real en 1545. Otras órdenes llegaron posteriormente, entre otras, los jesuitas y los juaninos. Los catecismos, cartillas, confesionarios y otros instrumentos que escribieron de manera manuscrita o impresa y en formato bilingüe no tenían la intención de castellanizar a los indios, sino que los religiosos aprendieran las diferentes lenguas. Las obras monolingües fueron también utilizadas. Debe pensarse que la labor de castellanización fue paralela a la de evangelización (Contreras, 2001: 11-12).

${ }^{3}$ De hecho, fue a partir de la segunda mitad del siglo XVIII cuando surgió con gran fuerza la intención de la Corona para que se establecieran escuelas en los pueblos de indios, donde se aprendiera el castellano. Los reyes borbones defendían los principios ilustrados de extender la enseñanza a toda la población, pues buscaban "sacarlo de la ignorancia". 
Chiapas, así como la independencia, quedan ligadas a la vida del fraile dominico y resulta complejo hacerlo, no sólo porque se trata de una época de transición, sino además porque fray Matías nació cuando esa provincia pertenecía a la capitanía general de Guatemala. Los esfuerzos de la historiografía sobre ambos temas han girado, en el caso del prócer chiapaneco, en varios asuntos, como la recreación de la vida de tan ilustre personaje: desde estudios elaborados al poco tiempo de que falleciera, o bien en resaltar sus aportes a la educación en escritos del siglo xx y hasta el inicio de los años ochenta del siglo xIx (Guillén, 1932; Corzo, 1946; Díaz, 1979; Cancino, 1981). Cabe decir que los autores posteriores a Guillén toman como base el escrito de éste.

Estudios más recientes nos ofrecen una mirada más objetiva, tanto de los logros de fray Matías de Córdova, como del estado de la enseñanza de las primeras letras en Chiapas y Guatemala. Por ejemplo, Dorothy Tanck de Estrada (1999), quien presenta el mejor panorama sobre la educación de los pueblos de indios entre 1750 y 1821, y Andrés Lira (1970: 117-140), que lo hace para Guatemala hacia 1824, se refieren la labor de fray Matías de Córdova: los dos hacen énfasis en el método para ayudar en la alfabetización de los niños. En el caso de Tanck, la autora explora en detalle lo que tiene que ver con la fonética; mientras que Lira analiza la utilización del método de Córdova en la enseñanza de primeras letras en Guatemala (Tanck, 1990: 141-160).

Un trabajo más enfocado específicamente a Chiapas es el de Irma Contreras García, quien se aboca a explicar la castellanización de las etnias de ese estado y la bibliografía desarrollada para ello. No es un texto acerca de fray Matías, sin embargo, importa incorporarlo en esta revisión porque la autora identifica y examina los esfuerzos realizados a través de los siglos por autoridades civiles y religiosas, en aras de lograr la castellanización de los indígenas, entre ellos ubica lo hecho por Córdova, si bien concluye que, en realidad, los avances no fueron ni han sido los esperados (Contreras, 2001: 46-47).

Por su parte, Adolfo Bonilla Bonilla ofrece uno de los análisis más completos sobre fray Matías de Córdova, pues discute y profundiza en los aportes económicos, políticos, étnicos, educativos y religiosos del fraile en el contexto de la ilustración en Centroamérica y en relación con el grupo de intelectuales de la época. Su análisis se basa, sobre todo, en el célebre ensayo del dominico: Utilidades que todos los indios y ladinos se vistan y calcen a la española y medios de conseguirlo sin violencia, coacción ni mandato (Bonilla, 2005: 215-229). Andrés Fábregas Puig, por su parte, considera relevante enfatizar el liberalismo de Córdova, heredado en el indigenismo mexicano (Fábregas, 2011:217-231). Finalmente, la investigación más reciente en torno a nuestro personaje es la de Morelos Torres Aguilar, quien publicó un par de artículos: en uno analiza la fundación de la escuela normal y el método de fray Matías de Córdova, aspectos que integra como capítulo en su libro sobre las iniciativas educativas realizadas en Chiapas a lo largo del siglo xIx (Torres, 2010: 139-168; 2016: 113-136; 2015: 43-66). Como se 
advierte, todos estos aportes han avanzado en el conocimiento de lo que fueron la vida y los legados de nuestro fraile; no obstante, considero que todavía importa profundizar en torno a algunos de esos aspectos y relacionarlos con la independencia chiapaneca.

En este artículo me interesa explorar la participación de fray Matías de Córdova en sucesos de carácter político, así como sus propuestas educativas, porque quiero conocer cómo la llustración y la independencia confluyeron en las acciones que emprendió en distintos momentos en el periodo estudiado. El texto está dividido en tres partes: en la primera abordo su biografía, haciendo énfasis en el carácter ilustrado de su educación e influencias; en la segunda describo uno de los conflictos que tuvo con su orden por el interés que tenía, junto con otros religiosos, en lograr la autonomía de la provincia dominica de Chiapas, que derivó, posteriormente, en su interés y el de la élite criolla chiapaneca en apostar por la independencia de esa provincia de la entidad mayor que era Guatemala. En la tercera, subdividida a su vez en tres apartados, se analiza la fundación de la Universidad Literaria, la Normal y la Sociedad Económica de Amigos en Chiapas; enseguida se describe la situación de la educación de primeras letras en la región y se revisa su principal propuesta educativa, basada principalmente en el método que elaboró. Finalmente, se aborda su esfuerzo de educación moral, filosófica y religiosa centrada en sus fábulas. Los materiales que han hecho posible este trabajo proceden del Archivo Histórico de Centroamérica (AHCA), del Archivo Histórico Diocesano de Chiapas (AHDC), así como del Museo del Libro (ML) y de la Hemeroteca Nacional (HN), ambos de Guatemala, ${ }^{4}$ además de la bibliografía localizada sobre el tema.

\section{Chiapas y fray Matías de Córdova}

Durante la etapa colonial, Chiapas perteneció a la capitanía general de Guatemala: primero, en su carácter de alcaldía mayor y, después, como una de las intendencias creadas por las reformas borbónicas (Olivera y Palomo, coords., 2007; Zebadúa, 2011). En ese Chiapas que después se independizó y decidió formar parte de México, hijo de padres y abuelos españoles, ${ }^{5}$ fue donde vio la primera luz en 1766 Matías de Córdova, concretamente en la ciudad de Tapachula, de la provincia de Soconusco. ${ }^{6}$ Tales datos constan en su acta de bautismo, que

${ }^{4}$ Estos materiales me fueron gentilmente proporcionados por el historiador dominico fray Eugenio Torres. También debo un agradecimiento a dos jóvenes historiadores: Omar Tenorio y Mario Zúñiga, quienes me ayudaron a localizar el material bibliográfico.

${ }^{5}$ Sus padres fueron el capitán don Pedro Rafael de Córdova y María Josefa Ordóñez; sus abuelos paternos fueron el capitán don Rafael de Córdova y doña Sebastiana Solís; los maternos fueron don Miguel Ordóñez y Gerónima de las Mercedes ("Ynforme de Don Matías de Córdova", Archivo Histórico Diocesano de San Cristobal [en adelante AHDSC], ff. 3v-5v).

6 "Copia del acta de bautismo de Fray Matías de Córdova", en "Ynforme de Don Matías de Córdova", AHDSC, fólder 2, ff. 3 y $3 \mathrm{v}$. 
presentó ante las autoridades como una de las pruebas de legitimidad, calidad, limpieza de sangre y buenas costumbres, con la intención de obtener una de las becas reales concedidas para estudiar en el seminario conciliar ${ }^{7}$ de Ciudad Real, en 1780, así como en los testimonios vertidos por los testigos que fueron llamados para atestiguarlo. Tenía catorce años cuando solicitó una beca con el fin de ingresar a los estudios de latinidad. Se le concedió una de las becas llamadas de fundación, gracias a que alegó pobreza y vocación sacerdotal; ambos aspectos fueron confirmados por los testimonios de varios testigos que, como era costumbre, fueron interrogados. ${ }^{8}$ Al cabo de dos años, gracias a ser becario de número, Matías pudo realizar en ese seminario los estudios de latinidad. Una vez concluidos, podía continuar con los estudios de filosofía.

El 17 de septiembre de 1782, Matías pidió al prior del convento de Santo Domingo de Ciudad Real, según consta en documento, ser admitido en la provincia de San Vicente Ferrer de Chiapas y Guatemala, de esa Orden. ${ }^{9}$ Una vez otorgada la entrada, inició su vida como religioso dominico, y continuó sus estudios de filosofía y teología durante los siguientes tres años. Fue en 1793 cuando consiguió obtener en su convento la cátedra de filosofía, ${ }^{10}$ siete años después, realizó el ejercicio literario conocido vulgarmente como de noche fúnebre ${ }^{11}$ y, aprobado nemine discrepanti (Guillén, 1932: 24), ${ }^{12}$ se le otorgó el grado de Doctor en Teología por el sínodo de la Universidad de San Carlos de Guatemala. ${ }^{13}$ Con el grado en mano, en 1801, obtuvo la cátedra de teología de su convento, ofreciendo en ambas - filosofía y teología-, lecciones ejemplares que pudieron no circunscribirse únicamente a las ideas escolásticas, pues, como señala Andrés Fábregas Puig (2011: 217-231), el saber del dominico respondía a un bagaje mucho más amplio y moderno. De estos años proceden dos de sus escritos más afamados: Modo de leer con vitalidad a los autores latinos de elocuencia (1801) y Prelaciones a los libros de elocuencia (1801) (Diccionario, 1995: t. 1, 957), redactados para apoyo didáctico de sus estudiantes de latín.

Comúnmente se asume que Matías de Córdova leyó varios autores modernos, entre ellos, Condillac y Adam Smith (Fábregas, 2011: 218). Aunque esto no puede constatarse en las

\footnotetext{
${ }^{7}$ Los seminarios conciliares fueron creados con el fin inicial de formar a los jóvenes para el sacerdocio, después ampliaron sus funciones y enfocaron también sus esfuerzos en enseñar jurisprudencia.

8 "Ynforme de Don Matías de Córdova", en AHDSc, fólder 2, ff. 1 y l v. El donante de los fondos para tales becas había sido el señor don Marcos Bravo de la Serna.

9 "Ynforme de Don Matías de Córdova", en AHDSC, fólder 2, f. 7.

10 "Actas del año 1814", en AHDSC, fólder 2, ff. 7 y $8 \mathrm{v}$.

${ }^{11}$ Examen de noche triste en el caso novohispano.

12 El autor se apoya en la noticia aparecida en la Gaceta de Guatemala, núm. 165.

${ }^{13}$ Recuérdese que la universidad era la única corporación que otorgaba grados en la etapa colonial, por tanto, fray Matías de Córdova tuvo que acudir a la Universidad de San Carlos de Guatemala, cuya jurisdicción incluía el convento dominico de Ciudad Real, para presentar los exámenes correspondientes y, aprobándolos, obtener el grado de doctor en teología.
} 
fuentes documentales revisadas, es un dato que se repite en las biografías escritas sobre él y que puede apoyarse tanto en el ambiente ilustrado que dominaba en la época a la que perteneció, como en las posturas y posteriores proyectos realizados por el fraile. ${ }^{14}$ La biografía elaborada quizá por alguno de sus colegas, a los quince días de su muerte y publicada en el periódico El para-rrayo de Ciudad Real el 4 de noviembre de 1828 así lo atestigua (Guillén, 1932: 15-17). Ciertamente el ambiente ilustrado logró reunir a un grupo importante de individuos que, nutridos de esa corriente, intentaron abrir nuevos caminos en diversos ámbitos de la vida guatemalteca y después chiapaneca, como ocurría en otros lugares de la América hispana. El fraile se encontraba a la altura de hombres ilustrados como José Campillo y Cosío (Herrera, 2013: s.p.), ${ }^{15}$ José María Peinado, ${ }^{16}$ Rafael Landívar (Recinos, 2013: 44-101) y Jacobo de Villaurrutia, ${ }^{17}$ entre otros. ${ }^{18}$ Las ideas de fray Matías de Córdova iban, pues, con las corrientes ilustradas y liberales de su momento, que cambiarían, a la par de como fueron los acontecimientos. Incluso, la condición criolla de estos individuos estaba en la base de su ideología, que buscarían imponer, como sucedió en otros lugares de la Capitanía General de Guatemala, como en la Nueva España.

Entre esos proyectos y acciones ilustradas se encontraba la fundación de la Sociedad Económica de Amigos de Guatemala, inaugurada en 1798 por el oidor de la Audiencia y doctor en leyes, Jacobo de Villaurrutia. Junto con otros individuos, estos personajes se reunían en tertulias patrióticas, como las llamaron, en una de las cuales surgió el proyecto de la sociedad,

${ }^{14}$ Algunos autores indican incluso que leyó e hizo críticas a Rousseau, Condillac y Adam Smith, pero no presentan evidencias sobre el asunto.

${ }^{15}$ José Campillo (1693-1743) fue un político, economista y hacendista español, autor del libro Nuevo sistema para el gobierno económico de la América (1782), que se considera sirvió para la introducción de las reformas en las posesiones españolas en el continente. En esa obra mostró una gran preocupación por el sufrimiento de los indígenas, incluso se considera que, en ese sentido, asemejaba la misma sensibilidad que mostró hacia ese sector de la población fray Matías de Córdova.

${ }^{16}$ José María Peinado (1769-1820)fue un terrateniente, comerciante y político guatemalteco; fue intendente de San Salvador, canciller de la Real Audiencia, regidor perpetuo de la intendencia de Guatemala y receptor general de Penas de Cámara en 1794.

${ }^{17}$ Criollo originario de Santo Domingo, Jacobo de Villaurrutia (1754-1833) fue un ilustrado abogado, político y literato. Realizó estudios en México y España; su preparación académica fue excelente. Invitado a ir a España, regresó a México como oidor de la Real Audiencia de Guatemala donde entre otras cosas, fundó junto con otros la Sociedad Económica de Amigos. Alrededor suyo se reunión un grupo de adeptos a la llustración. Colaboró en la Gaceta de Guatemala. En 1804, regresó a México nombrado como Alcalde del Crimen en la Real Audiencia de México. Posteriormente tuvo importante participación en el proceso de previo a la independencia, por lo que fue enviado a la península. Volvió a México en 1820 y suscribió el Plan de Iguala junto con Iturbide. De 1824 y hasta su muerte fue Ministro de Justicia en la Primera República Federal. Véase <http://www.menbiografias.com/app-bio/do/show?key=villaurrutiajacobo> [consulta: 4/11/2018].

${ }^{18}$ Precisamente, la intención de Bonilla en su artículo es ubicar a fray Matías dentro del grupo de intelectuales ilustrados guatemaltecos, algunos de los cuales derivaron hacia el liberalismo, o quedaron atrapados en medio, con ideas eclécticas entre ilustradas y liberales, uno de cuyos casos sería precisamente el fraile dominico. 
que fue aprobada por el rey en 1795. Su divisa fue "El zelo unido produce la abundancia" (Recinos, 2013: 107-108).

Como es sabido, estas sociedades económicas se crearon como una iniciativa ilustrada con orientación utilitarista, que buscaba impulsar el desarrollo económico e industrial de los lugares donde se establecieran, así como el intercambio de bienes y la mejora cultural de la población en general, por lo menos eso se decía en el discurso (Shafer, 1958; Ríos, 2002a; Torre, 2002). En algunos casos, sus objetivos podían ser más específicos y estar orientados a las necesidades de cada espacio. En todo caso, había situaciones básicas que trataban de promover, especialmente la mejora de la economía, la difusión de ideas científicas y la educación entre la población (Conzález, 1960: 133-139). Si bien se iniciaron desde mediados del siglo XVIII, en la América hispánica se fundó apenas una docena de éstas, algunas ya en el siglo XIX. En ningún caso fueron igualitarias, pues sus integrantes, quienes eran socios que generalmente debían pagar una cuota, se reclutaban de entre los miembros de la élite: nobles, prelados, comerciantes, políticos, letrados, propietarios de minas, entre otros. Pudo darse quizá la inclusión de maestros artesanos, pero si pasó en alguna, no fue la norma.

La Sociedad Económica de Amigos de Guatemala tenía todas esas características y sus objetivos particulares eran "promover y fomentar la agricultura, industria, artes y oficios en todos los ramos compatibles con los de la metrópoli por medio de discursos, demostraciones, premios y demás que acostumbran las de Europa" (Recinos, 2013: 207). Por eso, entre sus actividades se incluyó la promoción de diversos concursos para proyectos que fomentaran la industria, las artes o, como se señaló antes, la mejora cultural de la sociedad y que incentivaran su riqueza y producción.

Con ese propósito, la Sociedad Económica convocó en 1797 a un concurso que ofrecía como premio una medalla de oro y la patente como socio de mérito a quien escribiera el mejor ensayo o memoria sobre "la necesidad y medios de calzar y vestir a los indios como las otras clases decentes", lo que constituía uno de los objetivos de la sociedad, es decir, igualar a los indígenas logrando que vistieran a la española y dejaran de utilizar la ropa que el sistema colonial les había impuesto como símbolo de vasallaje (Recinos, 2013: 208; Bonilla, 2005: 216-217). El concurso se realizó y el premio fue concedido en diciembre de ese año a fray Matías de Córdova, quien escribió el ya mencionado ensayo Utilidades de que todos los indios y ladinos se vistan y calcen a la española... (Guillén, 1932: 16; Olivera y Palomo, coords., 2007: 24; Córdova, 1932: 244-254). La memoria fue publicada al año siguiente.

El título de la obra refleja la preocupación que centraría la atención de muchos de los ilustrados de ideas avanzadas de la época, es decir, cómo integrar y controlar a la mayoría de la población, que era de carácter indígena y castizo, dentro de sus propios proyectos. Esa población integraba un gran porcentaje del total, pero sobre todo representaba la mano de obra necesaria para cualquier empresa de mejora económica que tuvieran las élites criollas, 
por lo que resultaba necesario emprender proyectos que la "incluyeran" (Córdova, 1932; Recinos, 2013: cap. 4; Bonilla, 2005). No obstante, tal iniciativa no fue bien recibida por todos los miembros, pues en el seno de la corporación había una división tácita entre los más conservadores y aquellos más liberales, los primeros siempre oponiéndose a cualquier iniciativa que, según su punto de vista, atentara contra el orden social y, con ello, contra sus intereses.

\section{Acciones independentistas}

En 1802, Matías de Córdova aceptó una comisión del prior de su convento para viajar a Madrid a solicitar al rey la separación de los conventos de Chiapas de los de Guatemala, formándose con los primeros una provincia aparte. El argumento que se le dio para que defendiera la moción, y que sostuvo, fue apoyar una mejor administración de la provincia. Una carta de tres años después aclarará esos puntos, sin embargo, se especula que se trataba de un proyecto que descansaba mucho en los afanes independentistas y de autonomía de los grupos criollos privilegiados de la intendencia de Chiapas.

El 23 de marzo de 1805, Córdova informó, en una carta a su prior, haber recibido la carta de éste, enviada en agosto de 1804, pero que había sido interceptada por los ingleses y, finalmente, remitida al fraile dominico. En su misiva, fray Matías indicaba enterarse del despacho del informe que había solicitado, así como que se le pedía que llevara a Chiapas "sujetos que llenen las caritativas miras del plan de división" ${ }^{19}$ En cuanto al informe, apuntó que éste debía "hazer mucho peso para inclinar la balanza del soberano, tanto por la naturaleza del asunto, quanto por el buen nombre y merecida reputación de V.S.Y." ${ }^{20}$ En cuanto a los candidatos a llevar a la nueva provincia, indicó que se esforzaría por llevar religiosos que desagraviaran la falta que hasta entonces se había cometido de no proveer a esa provincia de suficientes maestros y ministros, sobre todo porque esto permitiría satisfacer "el empeño que se contrahe con Dios y con el Rey". ${ }^{21}$ Finalizaba su carta con la mención acerca de otras diligencias y trámites que su encargo le exigía cumplir. La misiva de Córdova permite suponer que había inconformidad de los dominicos de Chiapas por la poca atención prestada hacia ellos de parte del provincial guatemalteco.

Dos años después, el 10 de diciembre de 1807, se promulgó una cédula real en la que se otorgaba la gracia de la separación y erección de la provincia de Santo Domingo en Chiapas.22 Estando en esas diligencias en España y a punto de volver, fray Matías fue sorprendido por

\footnotetext{
19 "Carta de Fray Matías de Córdova fechada en Madrid el 23 de marzo de 1805", en AHDSC, fólder 2, f. 2.

20 "Carta de Fray Matías de Córdova fechada en Madrid el 23 de marzo de 1805", en AHDSC, fólder 2, f. 1.

21 "Carta de Fray Matías de Córdova fechada en Madrid el 23 de marzo de 1805", en AHDSC, fólder 2, f. 2

22 "Sobre elección de nuevo Prior para el Convento de Chiapas", 1811, AHDSC, fólder 2, f. 2.
} 
los acontecimientos provocados por la invasión francesa y, como muchos otros, tuvo que huir de Madrid, quedándose en el convento dominico de Santa Cruz de Granada y, finalmente, en el de Cádiz. ${ }^{23}$ Su viaje no estuvo exento de problemas, el primero de ellos fue la falta de dinero, por lo que, para solucionar esa situación, solicitó a sus superiores le permitieran tomar un préstamo de los fondos del convento dominico donde se encontraba, haciendo responsable a la nueva provincia de Chiapas. La respuesta fue que sólo era posible aceptar si se le nombraba procurador y se le conferían "los competentes poderes". Las noticias posteriores permiten decir que así se hizo, pues se enviaron cartas pidiendo informes sobre en qué se había basado para disponer de fondos. ${ }^{24}$

En todo ese tránsito de varios años, desde su arribo a la península hacia 1802 y su vuelta a Guatemala, Córdova seguramente tuvo contacto con hombres y experiencias que le dieron nuevas ideas para configurar sus posteriores proyectos ilustrados y liberales (Fábregas, 2011: 217-231). Fray Matías salió hacia Chiapas en 1809 y llegó en febrero de 1810. Algunos meses después, el vicario general de la Orden en España pedía que se confirmara la recepción de la patente y de las firmas de los documentos, indicaba el prelado "que la había presentado a su magestad la Suprema Junta Central para su pase."25 El 9 de junio de 1810 se expidió otra cédula que confirmaba la división en dos de la provincia de San Vicente Ferrer. La división formal en los hechos no fue tranquila, pues, como era de esperarse, la parte guatemalteca se opondría con los medios que considerara convenientes. El principal obstáculo fue que las patentes fueron enviadas equivocadamente al provincial en Guatemala. Esto ocasionó que no se ejecutara de inmediato la división, ni se verificaran los cargos de prior en los conventos chiapanecos donde se quedaron curatos sólo con párrocos interinos. Tampoco podían nombrarse lectores en el convento de Ciudad Real, pues todas esas responsabilidades correspondían al nuevo provincial y capítulo de Chiapas, "según y como convenga al beneficio público". Así lo hacía saber, en un extenso, emotivo y vehemente escrito, fray Matías de Córdova al gobernador y capitán general del Reino de Guatemala y al obispo de la jurisdicción. ${ }^{26}$ Sobre todo, les preocupaba a los interesados:

Cerrar la puerta a la arbitrariedad, poner en posesión de su prelacía al nuevo provincial, pues en el estado presente se hallan los priores, como con las manos atadas para promover la observancia de nuestras leyes y constituciones considerando que es una vehemente tentación contra la obediencia, el saber un súbdito, que con irse a Guatemala,

23 "Expediente sobre confirmación de sellos de cartas enviadas a Chiapas", 1809, AHDSC, fólder l, ff. 8 fs

24 "Expediente sobre confirmación de sellos de cartas enviadas a Chiapas", 1809, AHDSC, fólder 1, ff. 1-1v. Carta fechada en Cádiz el 25 de marzo de 1809.

25 "Expediente sobre confirmación de sellos de cartas enviadas a Chiapas", 1809, AHDSC, fólder f. 2. El subrayado es de la autora.

26 "Sobre separación de los conventos de predicadores de esta ciudad, de los de Guatemala", 1810, en AHDSC, fólder 2, ff. 12-15. 
tiene en cierto amagado al Prior. O quiera contrariar su voluntariedad, o castigarle algún exceso. Pero lo que más insta es el estar próximos a concluir el tiempo de mando de los priores de todos estos conventos, porque se necesita de Prelado Provincial que conforme las elecciones que los conventuales hayan echo de sus priores respectivos, lo contrario sería un seminario de dudas y escándalos sobre asuntos de tanta gravedad, como es la jurisdicción espiritual. ${ }^{27}$

Así, fray Matías pedía que las patentes fueran enviadas a los legítimos destinatarios, es decir, los dominicos de Chiapas. El documento fue recibido en Guatemala con las copias correspondientes de las cédulas reales en septiembre de 1810, haciendo parecer que todo se iba a arreglar. ${ }^{28}$ Pero, hacia mayo de 1811 , todavía no había solución, como lo hace saber una nueva misiva enviada al presidente de la Audiencia de Guatemala por cuatro dominicos, entre ellos Córdova, para que la nueva provincia se aprobara provisionalmente:

Sin embargo, de tenerlo todo prevenido en nuestras leyes, nos ha parecido conveniente, y aún necesario, atendidas las circunstancias en que se halla la provincia para la tranquilidad de nuestras conciencias ocurrir a V[uestra] S[uperioridad] Y[lustrísima] suplicándole que, como encargado por su magestad para que se verifique en todas sus partes la erección de ella [la provincia], se sirva aprobar la referida elección en los términos legales expresados, y confirmarla después, si no resultase ningún vicio en uso de la plenitud de potestad de que cargo de exercer, en vista de la imposibilidad de ocurso de la Santa Sede, pasando oficio sobre el particular al Exmo. S[eño]r. Presidente y dando cuenta de todo a su magestad con la brevedad posible, por convenir así a la puntual obediencia de la soberanía. ${ }^{29}$

Aún sin tener las patentes en mano, la nueva provincia comenzó a organizarse y a trabajar. En ese tenor, fray Matías en 1810 inició su labor de enseñanza de las primeras letras fungiendo como maestro (Guillén, 1932: 10), ${ }^{30}$ repartiendo su tiempo entre la política, su ministerio, su actividad docente y su escritura. De sus proyectos educativos hablaremos más adelante en detalle, por ahora continuemos con otros aspectos de su participación en los asuntos internos de la orden en Ciudad Real. Recordemos que eran tiempos de guerra y, si bien aparentemente ésta no afectó demasiado localmente como sucedía más al norte, en la

27 "Sobre separación de los conventos de predicadores de esta ciudad, de los de Guatemala", 1810, en AHDSC, fólder 2, f. 12

28 "Sobre División de los conventos de Guatemala de los de Chiapas", 1811, en AHDSC, fólder 2, ff, 1-2. El documento está firmado por Fr. Matías de Córdova, Fr. Antonio Estrada, Fr. Vicente Vives y Fr. Miguel Toriello.

29 "Sobre División de los conventos de Guatemala de los de Chiapas", 181l, en AHDSC, fólder 2, f. Iv.

${ }^{30}$ Guillén dice que inauguró una escuela en ese año, sin embargo, no fundamenta su aseveración en evidencia alguna, por eso sólo indico que comenzó a enseñar las primeras letras. Adelante, cuando aborde el tema de la instrucción pública, comentaré más al respecto, pues, al parecer, la escuela en realidad fue abierta en 1815. 
Nueva España (Zebadúa, 2011: 85-100; Vázquez, 2005: 53-72), las autoridades eclesiásticas pidieron información acerca de todos y cada uno de los eclesiásticos regulares y seculares, especialmente de los curas y sus coadjutores: su condición, calidad y conducta por las sospechas que había de la posible participación de algunos religiosos en cualquier evento de carácter independentista que se presentara. El remitente señaló en una misiva enviada el 29 de marzo de 1811:

No tengo motivo para presumir que ningún eclesiástico de esa diócesis se halle tocado del funesto vértigo, que tan cruentos estragos ha hecho en el reyno vecino de la Nueva España. Si alguno fuese capaz de infundir el menor recelo en tan delicado punto, la vigilancia pastoral de V.S.Y. atajaría muy luego el mal, ocurriendo a su eficaz remedio. Pero no hay precaución inoportuna en tiempos de tanta agitación [...].1.1

Incluso, se solicitaba que se comunicara de manera confidencial sobre el concepto que mereciese la conducta de cada uno y de sus pruebas "patriotismo, adhesión al lexitimo gobierno, y odio al espíritu de intrusión y rebelión, sin que se detengan V.S.Y. por no conocer a algunos personalmente, pues le será fácil tomar noticias fidedignas por medios confidenciales". ${ }^{2}$ Sólo se actuaría "internamente" si la ocasión lo ameritase. No obstante la urgencia de ese llamado, la autoridad eclesiástica de Guatemala no recibió respuesta inmediata del convento de Ciudad Real, pues el obispo de Chiapas remitió, el 30 de julio de 1811, una nueva carta a Córdova, que fungía como prior del convento y viceprovincial, pidiendo, además, información de las calidades del vicario de Tuxtla, don Manuel Antonio Figueroa, de quien se dijo: "ha hecho servicio de fomentar allí la Grana Cochinilla, y si en todo lo demás correspondiese su parte y desempeño, merecerá ser atendido para ejemplo de otros eclesiásticos". 33 ¿Acaso se suponía por las autoridades reales que podía haber un sujeto peligroso en Chiapas como lo hubo en la Nueva España con el cura Miguel Hidalgo? En otro documento de carácter reservado, el obispo enfatiza que era "en cumplimiento de las leyes de la Yglesia y del Reyno que nos previenen la parte y interés que debemos tomar en la conservación de la paz, ajuste y arreglo de la Sociedad Cristiana". ${ }^{34}$ En ello se resaltaba la petición de conocer el "concepto público" que se tenía de los religiosos. Fray Matías, al enviar el listado con los datos solicitados el 6 de agosto de 1811, adjuntó un texto en el que explicaba cómo había entendido tal expresión y cómo la calificaba:

\footnotetext{
31 "Documentos sobre conducta de religiosos", 1811, AHDSC, fólder 1, f. 1

32 "Documentos sobre conducta de religiosos", 1811, AHDSC, fólder l, f.lv.

33 "Documentos sobre conducta de religiosos", 1811, AHDSC, fólder l, f. 2.

34 "Documentos sobre conducta de religiosos", 1811, AHDSC, fólder 1, f. 2 y 2v.
} 
Debo hacer presente a V.S.Y. que por la última calidad indicada en el plan por la expresión concepto público unas veces lo entienda por la persuasión que tienen las gentes de ser el religioso aventurado en letras y buena conducta, por manera que puedan influir en sus opiniones, y en semejante caso lo explico en el plan con la palabra Bueno. Otras veces entiendo por la misma expresión la reverencia y atención que por eclesiásticos y en particular por párrocos les tienen, sin que esta razón los tenga por oráculos en los negocios graves de política. Y en esta virtud no debe perjudicar a nadie mi calificación de mediano, pues para el efecto sólo he tenido presente el caso, que a mi ver, ha movido la sabia previsión del gobierno. ${ }^{35}$

En cuanto a las muestras de patriotismo, se excusa de decir poco, debido al poco tiempo que llevaba en el cargo, pero señala enfáticamente: "puedo asegurar que en mi concepto es general el aborrecimiento a los injustos perturbadores de la tranquilidad". ${ }^{36}$ Se refería a aquellos clérigos que participaban activamente en la insurrección en otros espacios. Confiaba en las buenas noticias llegadas de la Vieja y Nueva España, se preciaba de los donativos hechos por los religiosos y, por tanto, pensaba que se podía contar con ellos en defensa de la justa causa. ${ }^{37}$ Después de esta afirmación tan categórica del fraile, en los documentos consultados no aparece más la sospecha de una posible participación de los religiosos dominicos o de la intendencia de Chiapas en la gesta insurgente. En cambio, dos años después, en 1813, por una circunstancia poco clara, el fraile Ramón Martí dejó su puesto "en encargo a fray Matías", y sin esclarecer el motivo señaló que:

Teniendo probabilidad de que se pretende atropellarme, y no hallando otro medio de evitarlo, me veo precisado a hazer ausencia de esta mi encomienda sin prejuicio del derecho que tengo de vindicar mi honor, y para que los bienes de mi convento no tengan el detrimento que pueden sufrir por quedar abandonado, por la presente y autoridad de mi oficio doi toda mi facultad al M.R. P. Prior de Santo Domingo Fr. Matías de Córdova [.... ${ }^{38}$

35 "Carta anexa a listado enviado sobre religiosos de la Orden enviado por Fray Matías de Córdova", en AHDSC, fólder 1, f. 1. "Listado sobre religiosos de la Orden enviado por Fray Matías de Córdova”, en AHDSC, fólder 2, f. 1. En el listado se menciona a un total de 35 frailes existentes en los cuatro conventos que componían la provincia en Chiapas. No a todos se calificó, seguramente por lo expresado por Córdova en el sentido de que no conocía a todos. Aquellos de los que mencionó "el concepto público" fueron 25 y de éstos, sólo seis le merecieron el concepto de bueno, el resto fueron medianos.

36 "Carta anexa a listado enviado sobre religiosos de la Orden enviado por Fray Matías de Córdova", en AHDSC, fólder l, ff. 1-lv.

37 "Carta anexa a listado enviado sobre religiosos de la Orden enviado por Fray Matías de Córdova", en AHDSC, fólder l, f. lv.

38 "Carta del comendador Fr. Ramón Martí al Prior del Convento de Santo Domingo, Fr. Matías de Córdova", en AHDSC, fólder 1, f. 1 . 
En 1815, de acuerdo con Flavio Guillén, nuestro personaje tenía los grados de presentado, maestro y el cargo de provincial de la provincia chiapaneca (Guillén, 1932: 16). En 1819, volvió a dirigirse al presidente de la Audiencia de Guatemala para que intimara al provincial de San Vicente de que no tenía jurisdicción sobre los conventos de Chiapas, e insistía en la devolución de las patentes recibidas desde 1810; pedía que se remitieran al maestro fray José Gascón, quien entonces ocupaba el cargo de vicario general de la orden para las provincias de España y las Indias. En tono fuerte, demandaba que:

Ninguno con pretexto alguno título o color se atreva a pedir directa o indirectamente la división, y creación de esta nueva provincia, ni intente impugnarla, ni contradecirla; y a todos los padres, y hermanos que pertenecen a los sobredichos conventos numerados y señalados para la nueva provincia mandamos bajo el mismo precepto, censura, y penas que obedezcan en todo y por todo al provincial de dicha provincia por nos creada, y a sus sucesores en adelante, y de ninguna manera al Provincial de la provincia de cuya obediencia, y jurisdicción los estimamos. ${ }^{39}$

Después de nueve años de haber obtenido la gracia de la separación, la comunidad dominicana en Chiapas todavía no lograba tener en sus manos los papeles que daban legalidad al hecho, al parecer, por la obstinación de sus correligionarios guatemaltecos. Asimismo, en él y en otros dominicos, seguía la idea de la separación, ya no sólo de la provincia de San Vicente Ferrer, sino también junto con otros sectores de la élite chiapaneca, la separación de toda Chiapas del Reino de Guatemala y, por supuesto, de la Corona española, como sucedió, finalmente, en 1821. De hecho, antes se había solicitado la erección de otra diputación provincial para Chiapas (Vázquez, 2005: 55-58; Rodríguez, 1984: 286-318).

Así, al calor de los últimos acontecimientos de la insurgencia, en uno de los actos quizá más radicales y de mayor envergadura en los que haya participado el dominico, y que no resultó de una iniciativa propia, sino del plan de un grupo de criollos que secundaron el pronunciamiento de Iturbide, en el Plan de Iguala, el 28 de agosto de 1821, durante la misa en el convento de Comitán, fray Matías de Córdova y fray Ignacio Barnoya instaron a los feligreses a declarar su independencia de España. Luego, el alcalde Camilo Celis, en cabildo abierto, completó la labor y los presentes se decidieron por la independencia, elaborando y firmando el acta respectiva (Pérez, 1988: 857-870).

En 1823, líderes políticos de toda la provincia se reunieron para declarar la independencia de Chiapas y su intención de unirse a México (Díaz, 1979: 84-85); entre ellos también estuvo Córdova. Pese a esa intensa participación en el proceso de independencia, no fue elegido diputado en la Junta Nacional Instituyente, y aparece como comisionado (junto al padre

39 "Carta de Fray Matías de Córdova de 6 de diciembre de 1819", en AHDSC, fólder 2, ff. 15. 
Domingo Carrascosa) en la redacción de un informe acerca de los medios que podrían echarse a andar en favor de los indígenas (Díaz, 1979: 84-85). En 1825, publicó en el periódico El Sol - de la ciudad de México - una carta en la que informó al ministro de Justicia y Negocios Eclesiásticos, Pablo de la Llave, el acuerdo del consejo de provincia de los dominicos de Chiapas de dar la libertad a los esclavos, pues argüía que en la Constitución del estado, a punto de darse a conocer "para desagravio de la humanidad se prohíbe la esclavitud". ${ }^{0}$ En la carta se indicaba que, en los conventos y haciendas de la orden que tuvieran esclavos, se les debía liberar, "a no ser que alguno quiera servir de mozo libre y pagado, si el Padre prior lo necesita, a quien se encarga su educación e ilustración". 41

Córdova, en el terreno educativo, continuó su labor como maestro de primeras letras e incluso tuvo oportunidad en 1824 de responder al Ilamado del gobierno de Guatemala para premiar: "a quien mejor escribiese una cartilla que simplifique el método de enseñar a leer y escribir y expresar con más claridad los deberes del cristiano y del ciudadano" (Lira, 1970: 138-139). Fue a fray Matías de Córdova a quien correspondió el premio que consistió en la publicación de su método -en julio de 1824- (Córdova, 1824). Se trataba de un texto que había preparado, según él mismo anotó, desde 1810, cuando se hizo cargo de la escuela de primeras letras en su convento.

Otra iniciativa en la que participó, quizá la última de su fructífera vida, fue la publicación de un periódico en Ciudad Real, uno de los dos primeros diarios que hubo en Chiapas en esos años posteriores a la independencia. Se trató de El Para-rayo de la capital de Chiapas, cuyo primer número apareció el 3 de octubre de 1827. Periódico de tendencia conservadora cuyo título aludía a la división ideológica que había surgido después de 1820, y cuya efervescencia, en opinión de Córdova, había que parar. Otro periódico en el que también escribió, duró dos años y medio en circulación (Martínez, 2018). Es decir, sobrepasó la vida de fray Matías. En 1828, murió este prócer, dando fin a una vida que corrió a la par de acontecimientos y procesos de suma importancia para Chiapas, Centroamérica, México y América Latina. Analicemos ahora su contribución a la instrucción pública en Chiapas.

\section{Las propuestas educativas de fray Matías de Córdova}

Explorar el tema de las propuestas educativas de fray Matías de Córdova requiere de un conocimiento (aunque sea mínimo) de las condiciones de la educación pública en Chiapas a fines del siglo XVIII y la primera década después de la Independencia, pues tanto sus aportes como su vida, se inscribieron en el contexto ilustrado e independentista en el tránsito del

\footnotetext{
${ }^{40}$ El Sol, 28 de agosto de 1825, p. 276.

${ }^{41}$ El Sol, 28 de agosto de 1825, p. 276.
} 
virreinato a la república. Otro punto importante es que sus propuestas educativas particularmente se dirigieron a los indígenas y castas, pues era de sumo interés para las élites chiapanecas educarlas. Asimismo, fray Matías aportó, al parecer, también sus esfuerzos en la creación de la Universidad Literaria de Chiapas (González, 1960: 154). Veamos las condiciones de la enseñanza de las primeras letras hacia fines del XVIII.

Chiapas contaba con una población indígena de 71,595 personas, es decir, el 70 por ciento de la población total (Tanck, 1999: 281). Entre ellos, principalmente tzotziles y tzeltales. La intención de las autoridades y de la élite era instruirlos en las primeras letras, que aprendieran a leer, escribir y contar, además de continuar enseñándoles la doctrina cristiana. Evidencia de esto fue la orden que envió la Audiencia de Guatemala al intendente de Chiapas para que informara sobre el número de maestros de primeras letras que había en su jurisdicción, pues debía darle cumplimiento a varias cédulas reales - de 1764 a 1782 - relacionadas con el establecimiento de escuelas y el artículo 14 de la ordenanza de intendentes, en la que se mandaba preferir a indios que supieran el idioma castellano para ocupar los puestos de gobernadores y alcaldes. Los contadores de Ciudad Real informaron acerca de los pueblos donde había escuelas, proporcionaron el nombre del maestro y el número de tributarios residentes en cada pueblo. Eran 39 preceptores y uno adicional mencionado en otro informe, 25 escuelas estaban en la región de Ciudad Real, siete en el área de Tuxtla y ninguna en la región del Soconusco (Tanck, 1999: 281). El sueldo más alto era de 108 pesos anuales en el pueblo de Salto del Agua, subdelegación de Palenque; y más de la mitad ganaba 96 pesos anuales. ${ }^{42}$ El informe, sin ser triunfalista, hablaba en buenos términos de lo que se estaba haciendo. Otras opiniones iban en sentido contrario, señalando que los proyectos de crear escuelas para que los indios aprendieran el castellano eran un fracaso, así lo aseguró hacia 1812 el arzobispo de Guatemala, Pedro de Cortés y Larraz (Contreras, 2001: 30-31).

Aún más, un documento escrito por el fiscal de la Real Hacienda de Chiapas, Sebastián Esponda y Olaechea, muestra abiertamente la preocupación por la educación de la población indígena, y sugiere posibles soluciones (Tanck, 1999: 211-214). De acuerdo con Tanck, Esponda conocía a fondo el tema y escribía con pleno conocimiento de causa. El fiscal proponía el establecimiento de escuelas para los niños indígenas, porque éste sería el principio de la felicidad "de esos miserables". Señalaba enfáticamente que era un deber del Estado "facilitar la educación religiosa", algo que a esas alturas no comprenderían ni aprobarían todos, por ejemplo, las autoridades de la intendencia de México, que creían que esto era más bien

\footnotetext{
42 La estadística completa y un mapa se hallan en el mismo texto de Tanck (1991: 282-284). Otra información mucho más general la obtenemos de Contreras García (2001: 43), quien señala que la diócesis de Guatemala contaba con 431 pueblos de indios, de los cuáles sólo 103 declararon contar con escuelas de indios, donde supuestamente debían aprender el castellano, sin embargo, de esas 103, sólo 88 curas declararon hacerlo, de las 15 restantes, siete indicaron enseñar doctrina cristiana y el resto no agregó nada.
} 
una obligación de los padres de familia. También recomendaba pagar mejores sueldos a los maestros y sugería que fueran diez pesos al mes; proponía la supresión de las cofradías fundadas ilegalmente y que sus fondos fueran utilizados para proveer a las escuelas, aunque también reconocía que esto era una acción que podía causar mucho revuelo entre los indígenas, y que sería mejor emplear el dinero del fondo general de comunidades guardado en Ciudad Real, "porque contenía caudal suficiente para emprender cualquier proyecto de esta naturaleza" (Tanck, 1999: 212). Evitarían así las quejas de los indígenas pobres por el pago de cuotas extras para la enseñanza, pues, además, existía ese fondo. Asimismo, mencionaba la falta de interés de los familiares en enviar a sus hijos a las escuelas, en parte debido al maltrato de algunos maestros y a su poca capacidad. También señaló que los padres de familia suponían que sus hijos sólo irían a perder el tiempo dejando de ayudar en las labores del campo. La solución necesaria, apuntó, era encontrar maestros capaces de cumplir con su labor y convencer a los padres de que así se haría. Por tanto, el preceptor tendría como tarea persuadir a los padres, además debía ser bilingüe para facilitar la enseñanza del castellano.

El fiscal Esponda y Olaechea confiaba en que "con la ayuda de párrocos y subdelegados, con premios para los alumnos más sobresalientes en los exámenes públicos y con cuatro becas para seguir estudios avanzados en el seminario de Guatemala [habría] un futuro dichoso para los indios" (Tanck, 1999: 212). Incluso pensaba que podría prepararse a los niños indígenas para ocupar varios puestos, tanto en la administración civil como en la religiosa. Creía que su atraso se debía a la actitud de los blancos, a la creencia de que debían de permanecer en abatimiento y humillación: "para que no se ensorbezcan y alcen y de que sólo deben ser gobernados por el rigor" (Tanck, 1999: 213). ${ }^{43}$

El fiscal afirmó que la distancia entre blancos e indígenas, más que por el idioma, se debía al maltrato y actitudes de superioridad de los primeros hacia los segundos; si se quería integrar a los indígenas, había que tratarlos con respeto y justicia, si no se hacía así, existía el peligro de que se rebelaran (Tanck, 1999: 213-214). Ideas como éstas recibieron apoyo por parte de la Sociedad Económica de Amigos de Guatemala, y permitieron a fray Matías de Córdova escribir su ensayo sobre la Utilidad de que todos los indios y ladinos vistiesen y calzaran a la española. Quizá el propio fiscal pertenecía a la Sociedad de Amigos, pero por ahora no podemos asegurarlo.

Además de las escuelas en los pueblos indígenas, había escuelas de primeras letras en los conventos. En general, entre unas y otras, podemos decir que era atendida en lo posible esa enseñanza tanto para los indígenas como para las castas a comienzos del siglo XIX. Sin embargo, los resultados no parecen haber sido los óptimos. El esfuerzo que hizo Matías de Córdova en 1810 para fundar una escuela en el convento de Ciudad Real nos confirma esa

\footnotetext{
${ }^{43}$ Partes del informe de Esponda citados por Tanck (1999).
} 
situación. Los diferentes autores hablan sobre esta fundación (Guillén, 1932; Pérez, 1988; Díaz, 1979; Lira, 1970), sin embargo, no ofrecen evidencias documentales sobre esto, al parecer, como se verá abajo, la fundación fue en 1816.

Así como este esfuerzo, se harían otros en los años subsecuentes; todos originados por el ímpetu de la ilustración, porqueen esos momentos estaban impregnados de la impronta de Cádiz de 1812 y del liberalismo. Mediante la instrucción ofrecida a los jóvenes, se buscaría sentar las bases de la formación de los ciudadanos, sobre todo de que fueran aptos para una vida civil y política, como lo comenzaron a exigir los nuevos tiempos. Así, en 1815 se enviaron a fray Matías "los correspondientes oficios de ruego y encargo a los Prelados de las Comunidades Religiosas de esta ciudad para el establecimiento de Escuelas de Primeras Letras, que previene la Real Cédula de 7 de junio de 1815", legislación emanada de Cádiz. Córdova contestó al deán y gobernador del Obispado, don Manuel de Esnaurrízar, el 15 de julio de 1816, que contaba con una pieza en su convento para tal fin; además de que nombraría al P. fray Lino Navas como preceptor bajo la dirección del subprior, fray Francisco. Asimismo, mencionó su inauguración:

en cuya virtud, y de conformidad con el dictamen del teniente letrado he provehido en esta fecha, entre otras cosas, que el sábado 2 del corriente, reunidos los muchachos en las casas consistoriales, sean conducidos desde allí a la citada Escuela con el júbilo y aparato que corresponde a la grandeza del establecimiento, para que el público haga el debido aprecio y concepto que se merece: que se ponga en noticia de V.S. para que se sirva dispensarle toda su protección, como lo encarga Su Majestad en la citada real Cédula, y que si lo tuviere a bien, para más solemnizar el acto de la apertura de la Escuela se digne prestar su asistencia para el expresado día $2^{\circ}$ del

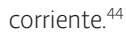

La fundación de esta escuela obedecía al esfuerzo de las autoridades civiles y diocesanas, así como a los afanes de los frailes por la educación pública. La experiencia adquirida por fray Matías de Córdova en esta empresa educativa lo llevó a identificar los problemas que enfrentaban los niños indígenas para avanzar en el aprendizaje de la lectoescritura. De esos apuntes surgió su famoso Método, que, como se sabe, fue solicitado por las autoridades guatemaltecas en 1824. En este momento, la provincia de Chiapas no estaba incorporada a México, pues no tomaría esa decisión sino hasta septiembre de ese año. El 2 de enero de 1824, el gobierno de Guatemala pidió a todos los jefes de las provincias información acerca del estado de las escuelas, los métodos y el número de alumnos y maestros. Se pretendía tener un panorama general para tomar las medidas adecuadas y resolver el problema de la educación. En el decreto se invitaba "a los hombres de letras ofreciendo [un] premio a quien mejor

44 "Carta al Deán y Gobernador del Obispado de Chiapas", 15 de julio de 1816, en AHDSC, fólder 1, f. 3 
escribiere una cartilla que simplifique el método de enseñar a leer, escribir y expresar con más claridad los deberes del cristiano y del ciudadano" (Lira, 1970: 123; Tanck, 1990: 141-162). El premio sería costeado por los fondos de propios, arbitrios y bienes de comunidad. No sabemos si todas las provincias enviaron sus respuestas, pero la municipalidad de la ciudad de Guatemala sí lo hizo, haciendo llegar un expediente donde dio cuenta de todos los solicitados, lo que permite conocer las condiciones de la educación en esos momentos (Lira, 1970: 122-123). ${ }^{45}$ Destacan, en particular, los "Estatutos de la Escuela de San José Calasanz, que fundó [en 1792] el Señor Don Cayetano Franco y Monroy", arzobispo de Guatemala.46 En los estatutos se puntualizan los aspectos concernientes a la enseñanza, su organización, requisitos y los textos a seguir; los preceptos contenidos estaban sustentados en una filosofía y debían seguirse en las escuelas de Chiapas. Por su importancia, ofrecemos algunos aspectos de los estatutos. Eran tres los objetos de la instrucción de la juventud: ciencia, costumbre y religión. "Cultivar el entendimiento de los jóvenes y adornarle de todos los conocimientos que su edad permite; ratificar su corazón por principios de honor y de integridad, y formar en ellos al hombre". ${ }^{47}$ Se dice claramente que la educación pública es el termómetro de la elevación o decadencia de los estados. ${ }^{48}$

\section{La Sociedad Económica, la Universidad Literaria, la Escuela Normal}

El 12 de septiembre de 1824, se firmó en Ciudad Real la adhesión de Chiapas a la República Mexicana como uno más de sus estados (Santiago, 1998: 38). No obstante, para ese entonces funcionaba ya en Ciudad Real la Sociedad Económica de Amigos de Chiapas, una de las últimas en ser fundadas en territorio hispanoamericano antes de las guerras de independencia (Shafer, 1958: 248-249; Ríos, 2002a: 103-161). Esta sociedad, de carácter ilustrado, se fundó años antes de la independencia de la provincia (en 1819), al calor de los conflictos existentes entre los conventos dominicos de Chiapas y Guatemala, cuando ya se querían mostrar las diferencias entre una y otra región en este terreno. En aquélla participó activamente fray Matías de Córdova, quien incluso dio el discurso de inauguración como vicedirector el $1^{\circ}$ de abril del citado año. Como todas las de su tipo, tenía la intención de promover la

\footnotetext{
45 "Ynforme que da la Municipalidad de Guatemala en orden a las Escuelas en primeras letras en esta corte", en Archivo General de Centro América [en adelante, "Ynforme que da la municipalidad", ACCA], leg. 1079, exp. 23067. Diez eran las escuelas existentes en la ciudad de Guatemala: tres eran públicas, cuatro de las órdenes religiosas y el resto privadas. De acuerdo con Andrés Lira, también existían dos beaterios donde se daban clases a las mujeres, y por eso no eran consideradas escuelas, pues los conocimientos que impartían eran para formar a la mujer para el hogar. En todas enseñaban la doctrina cristiana como parte de su currículum.

46 "Ynforme que da la Municipalidad", ACCA, leg. 1079, exp. 23607, f. 1.

47 "Ynforme que da la Municipalidad", AcCA, leg. 1079, exp. 23607, f., 1.

${ }^{48}$ Véase, por ejemplo, las "Reglas para la fundación y el gobierno de los maestros en la enseñanza de los niños de ambas escuelas, 1789", en "Ynforme que da la Municipalidad", AcCA, leg. 1079, exp. 23607, f. 14v.
} 
agricultura, las artes, el comercio y la ilustración. Sus estatutos los redactaron tres individuos y la organización contemplaba cuatro comisiones, estaría integrada por socios de número y honorarios. Entre sus actividades, llevó la primera imprenta a Chiapas en 1826 (López, 1960: 880-882).

En el caso de la educación universitaria, el 12 de febrero de 1826, fue inaugurada la Universidad Literaria de Chiapas (Trens, 1942: 324-326; González, 1960: 154; Morelos, 2015 : 112-114) en el edificio que había sido del seminario. González Orellana afirma que Matías de Córdova participó en la fundación, aunque no aclara todavía cómo lo hizo. Él y otros autores argumentan la formación de una comisión de entre tres y cinco individuos que se encargarían de elaborar los estatutos, sin embargo, ninguno menciona quiénes fueron esos hombres, quizá uno de ellos fue Córdova. También se afirma que era rector de la Universidad cuando acaeció su muerte en 1828 (Pérez, 1988: 869; González, 1960: 154) y, en el caso del estudio más reciente, Torres Aguilar no indica nada al respecto. De hecho, los primeros años de la universidad fueron difíciles por la falta de profesores y fondos, quizá también de estudiantes (Torres, 2015: 114). No obstante, no sabemos quiénes fueron sus primeros rectores, profesores y alumnos.

Ahora bien, además de esclarecer en algún otro momento esa probable participación del prócer en la empresa universitaria, algo más significativo es señalar que esa fundación se originó al calor de las propuestas educativas emanadas de la Constitución de Cádiz, ${ }^{49}$ de origen en los proyectos franceses, y formaba parte del proceso que se seguía en otros estados (Ríos, 1994: 1-30; 1998: 193-233). La élite chiapaneca buscó contar con un establecimiento educativo de carácter universitario que le permitiera tener otro elemento para consolidar su autonomía, así evitaba enviar a sus jóvenes a la Universidad de Guatemala, o a alguna otra a formarse y obtener los grados académicos (González, 1960: 109; Santiago, 1998: 38; Torres, 2015: 114). Era la misma aspiración de los grupos privilegiados de otros estados, pues cada uno fundó un establecimiento de estudios superiores o universitarios fuera, bajo el nombre de Instituto (como lo hicieron Jalisco, Oaxaca, Estado de México, Zacatecas y Chihuahua), o intentaron reformar sus colegios (Ríos, 1998: 193-233).

La Universidad Literaria de Chiapas nació, pues, bajo una idea que puede considerarse autonomista, con el fin consolidar la independencia de los recién constituidos estados, pero también ilustrada, es decir, con el carácter de ser la institución que ofrecería los estudios de segunda y tercera enseñanza, como se ordenó en Cádiz en 1812, y después en el Plan Quintana de 1814, que específicamente ordenó la creación de "universidades de segunda" en

\footnotetext{
${ }^{49}$ Las propuestas educativas de Cádiz de 1812 fueron, grosso modo, las siguientes: 1) Establecer escuelas de primeras letras en todos los pueblos de la monarquía; 2) Aumentar el número de Universidades; 3) Se seguirá un plan uniforme en todo el Reino; 4) Se creará una Dirección General de Estudios que cuidará de la inspección de la instrucción pública; 5) Se declara la libertad de imprenta (González, 1960: 178; Meneses, 2001: 72-73)
} 
todas las capitales de provincias (Ríos, 2015: 273-274). 50 Por tanto, en ésta se abrieron las cátedras de latín, filosofía, teología, cánones y derecho civil; otorgaba los grados de bachiller, licenciado, maestro y doctor.

Por otro lado, al designarla como literaria, aun cuando mantuviera el nombre de universidad, al agregarle ese adjetivo pretendía establecerse una diferencia con las antiguas corporaciones universitarias, además de intentar hacerla partícipe del saber universal que denotaba ese calificativo, como se hizo en Guadalajara a fines del siglo XVIII, y se haría también en Yucatán con su universidad en 1824. En ese sentido, la historia de la institución chiapaneca aún necesita profundizarse.

Otro proyecto educativo surgió de la iniciativa de Córdova en 1828, poco antes de su muerte: la erección de una escuela normal en Ciudad Real, que pudo estar en las primeras de su género. Al respecto, el Congreso chiapaneco dictó lo siguiente:

\begin{abstract}
El Honorable Congreso se ha servido resolver lo siguiente: $1^{\circ}$.- El gobierno, de acuerdo con fray Matías de Córdova, hará que antes de sesenta días se funde en esta ciudad, la Escuela Normal de Enseñanza Primaria, bajo el nuevo método inventado por dicho religioso, quien, como autor, ha ofrecido dar un curso. $2^{\circ}$.- Cómo los deseos del Congreso tienden a que los frutos del plantel se generalicen, en utilidad del estado, el Cobierno, con tal objeto, invita a cada partido (distrito) para que envíe de dos a cinco individuos ya instruidos para que aprendan el método, puedan obtener y desempeñar las escuelas que han de establecerse. $3^{\circ}$.- Los que vengan a instruirse en la Normal, serán sostenidos con fondos de sus respectivos municipios y, en caso de no tenerlos, el Gobierno del Estado erogará con ese fin hasta la cantidad de mil quinientos pesos. $4^{\circ}$.- El Gobierno dictará las demás providencias que crea conducentes al logro de tan interesante objeto. Imprímase y circúlese. Dios y Libertad. Capital de Chiapas. Ignacio Velasco (Guillén, 1932: 51-52). ${ }^{51}$
\end{abstract}

El 18 de mayo de 1828 fue inaugurada esta escuela en una lucida ceremonia a la que asistieron el gobernador, el prelado y los miembros de la élite criolla. El director fue Paulino

${ }^{50}$ El plan Quintana especificaba lo siguiente: 1) Creación de una Dirección General de Instrucción Pública con sede en Madrid y subsedes en las principales ciudades de la Península y América; 2) Homogenización y uniformización de los estudios. 3) Gradación y jerarquización de los estudios, serían de primera, segunda y tercera enseñanza y se pasaría gradualmente del más bajo al más alto; 4) Financiamiento Público de la educación: los ayuntamientos costearían las primeras letras; la diputación los de segunda o secundarios, y el gobierno central los de la superior. 5) Creación de "universidades de segunda" en las principales capitales de provincias; 6) Erección de un instituto o academia nacional, a la manera francesa, en las principales capitales del reino, en este caso, en la Nueva España (Ríos, 2015: 273).

${ }^{51}$ En Zacatecas, en 1825, también se fundó una escuela normal llamada de la Constitución. En este caso, se le atribuye ser la primera normal de México, pero, en ambos casos, en Chiapas y en Zacatecas, se trata de ganar la primacía de haber sido los primeros en fundar una normal, cuando quizá ese atributo en realidad no tenga tanta importancia. Para el caso de Zacatecas (véase Ríos, 2002: cap. 2, especialmente la parte correspondiente a la primera república federal. 
Trejo, quien pronunció un emotivo discurso en el que se preció de ese invento (el método de Córdova) que se había hecho en Chiapas, "rincón casi ignorado del resto del mundo" (Guillén, 1932: 52), que haría posible superar la barbarie, formar a los hombres, a los ciudadanos, era el tiempo de que muchos más supieran leer para superar la opresión y ganar la libertad. "Solamente los ilustrados son capaces de ser independientes y libres" (Guillén, 1932: 52). Concluía pidiendo ser "gratos, al digno hijo de nuestro suelo que inventó el medio de dar ilustración necesaria a las masas populares. Seámoslo a nuestro benéfico gobierno que ha procurado vencer todos los obstáculos, que se oponían al establecimiento de este Instituto" (Guillén, 1932: 52). Sin duda, el director se refería a fray Matías, y es interesante saber cuáles fueron esos obstáculos que se encontraron en el camino. La escuela normal funcionó durante veinte años, pero fue cerrada porque las facciones o grupos políticos estaban divididos, y quien se posicionaba en el poder tomaba decisiones que interrumpían la continuidad de las instituciones, sobre todo si las habían fundado los enemigos políticos.

\section{El método de Fray Matías y sus resultados}

Es oportuno conocer cuál era el método seguido por las escuelas a fines de la etapa colonial, para así valorar en su justa dimensión la propuesta de fray Matías de Córdova en 1824. Contamos al respecto con el informe presentado por la municipalidad de la ciudad de Guatemala, precisamente en el año en el que comenzó a conocerse el Método de Córdova. En este informe se incluían unas "Reglas para la fundación y el gobierno de los maestros en la enseñanza de los niños de ambas escuelas", que puntualizaban aún más las condiciones en las que se daba la enseñanza. Escritas en 1789, comienzan con la edad en la que los niños debían iniciar su instrucción, quedaba claro que no se debían admitir menores a seis o siete años. ${ }^{52}$ Ratificaban los horarios de asistencia e indicaban las actividades, la primera de éstas, la asistencia de los niños a la misa y, para finalizar el día, el rosario. En medio quedaban las actividades de aprendizaje. ${ }^{53}$ Las "Reglas", además de señalar los libros de texto,, daban ejemplos puntuales de cómo enseñar y también subrayaban que debía seguirse la emulación como una forma de inspiración para los niños. Ésta consistía en aplaudir "a los aplicados y a los que adelantan a los demás para que estos se animen a imitarles o avanzarlos si fuere posible." 55 En el documento se valora mucho esa práctica por la fuerza que, se dice, "tiene en el ánimo de los jóvenes, por las posibles envidias que naturalmente se despierta en algunos al verse superados por sus semejantes". Se advierte que se debía evitar la posibilidad de

\footnotetext{
${ }^{52}$ Reglas para la fundación, f. 8v.

${ }^{53}$ Reglas para la fundación, f. 9.

${ }^{54}$ Reglas para la fundación, f. 9.

${ }^{55}$ Reglas para la fundación, f. 10v.
} 
peleas, formación de bandos, entre los de la clase y con los jóvenes de otras escuelas. Se debía enseñar a amar y a ayudar, y dar a entender que la mejor prenda del hombre es hacer el bien a los demás. ${ }^{56}$

En otro tenor, se prohibía colocar pinturas o cuadros inútiles o indecentes en las paredes del salón de clases. En cambio, proponía colocar una pintura del santo patrono en la pieza principal de la escuela y en diferentes lugares estampas con la ley de Dios, el credo y pasajes de la biblia. ${ }^{57}$ El día del santo patrono sería de fiesta para la escuela y se celebraría con una misa y ejercicios literarios para los niños más aventajados. Eran prácticas con un sentido muy religioso, ${ }^{58}$ pues incluso se pedía que a los párvulos se les enseñara a ayudar en la misa. ${ }^{59}$

Enseguida se detallaban los libros y contenidos que debían seguirse en cada ramo de enseñanza, discutiendo autores y reflexionado sobre sus pros y contras. ${ }^{60}$ Por ejemplo, para aprender a leer y escribir, se habían aprobado El arte de escribir por reglas y $\sin$ muestras, ${ }^{61}$ el Catecismo del padre Ripalda y el Fleury; para las cuentas se recomendaba tanto el Tratado de Aritmética de Padilla como su Método. ${ }^{62}$ Por último, se hablaba de la limpieza de la escuela y en cuáles actividades se ayudaría a los niños pobres, pues a ellos no se les pediría ninguna contribución, por lo que "serán los que barran la escuela y limpien las paredes, mesas, escaños". ${ }^{63}$ Hasta aquí el reglamento, que, como observamos, se elaboró con el fin de lograr los mejores resultados en la difusión de las primeras letras a la mayoría de la población, cabe decir que estamos hablando únicamente de escuelas en la ciudad de Guatemala, por lo que resulta difícil que hayan asistido a ellas muchos niños indígenas.

En este informe municipal de 1824, se señala que en las diez escuelas de la capital se empleaban distintos métodos y libros; además, se expresa la preocupación de las autoridades por encontrar el método más apropiado para que los niños aprendieran a leer y escribir. Esta inquietud se reforzaba por el número de los alumnos que tenían las diez escuelas de la municipalidad: 612, ${ }^{64}$ una cantidad que puede considerarse mínima en relación con el total de niños que tenía la ciudad y que aprendían unos saberes considerados en su época como imprescindibles para llegar a ser ciudadanos. Esa problemática llevó a convocar a los hombres de letras para proponer un nuevo método y, como ya se comentó, a quien se le recibió la

\footnotetext{
${ }^{56}$ Reglas para la fundación, f. 10v

${ }^{57}$ Reglas para la fundación. f. 11.

${ }^{58}$ Reglas para la fundación, f. 11 v.

${ }^{59}$ Reglas para la fundación, f. 13.

${ }^{60}$ Reglas para la fundación, ff. 1lv-15.

${ }^{61}$ Reglas para la fundación. f. 11 v.

${ }^{62}$ Reglas para la fundación, f. 12.

${ }^{63}$ Reglas para la fundación, ff. $13 \mathrm{v}$.

64 "Informe de la Municipalidad de Guatemala", AGCA, leg. 1074, exp. 23067, ff. 44-46.
} 
propuesta fue a fray Matías de Córdova, quien envió al Ayuntamiento de Guatemala desde Ciudad Real "tres quadernitos sobre método fácil de aprender a leer y escribir" ${ }^{65}$

El Método, cuya formación inició el fraile en 1810, fue impreso en Guatemala en 1824 por la imprenta nueva a cargo de Juan José de Arévalo. En su primera página lleva el título de Método fácil de enseñar a leer y escribir, en la segunda página, otra portada con el título Discurso sobre las dificultades que ofrece el método corriente de enseñar a leer y escribir, y sistema que se propone para facilitar la enseñanza primaria. Se agregaba que "se hallarán estos impresos en la tienda del C. Víctor Savala". ${ }^{66}$ Cabe hacer esta aclaración porque, al parecer, hubo una segunda edición titulada Nuevo método para la enseñanza primaria, publicada por el estado de Chiapas, aunque no se conoce bien el año. La publicación que utilizamos aquí está dividida en cinco partes: "llustración popular", "Advertencia a los maestros", "Cartilla", "Reglas para leer en el sistema antiguo" y "Ortografía" (Córdova, 1824). El Método ha sido analizado ejemplarmente tanto por Dorothy Tanck (1990: 142-147), como por Morelos Torres Aguilar (2015: 57-65), quien usa la ya mencionada segunda edición, sin aludir a la primera. Debido a los estudios ya realizados acerca del Método, aquí haré hincapié solamente en algunos puntos.

Córdova señalaba a las autoridades que en América había hombres instruidos en todo género de ciencias, pero "no habría ilustración popular si la mayoría de sus individuos no saben leer, o a lo menos escribir". Se preguntaba si en poco tiempo pudiera ser posible que los americanos supieran hacerlo; culpaba de esa situación al largo tiempo que los niños tenían que gastar en el aprendizaje, que los padres argumentaban como excusa para no enviarlos a la escuela. De ahí que, necesitando de sus brazos para el trabajo, "la mayor parte de la gente de color, y casi todos los indios no sepan escribir y leer" (Córdova, 1824: 3). Además, indicaba que un niño podía aprender "a leer con perfección y a escribir, aunque sin buena forma" y necesitaba sólo de sesenta días, ocupando una hora por la mañana y otra por la tarde para lograrlo. Antes de pasar a algunas especificaciones del método, conviene detenerse por un momento en esa cita en la que Córdova menciona a la "gente de color", pues ésta era generalmente invisibilizada en los discursos de la época. A nuestro fraile apenas le mereció esa alusión que sorprende, aunque también Ilama la atención que no haya profundizado en ello. De hecho, el ocultamiento de ese sector ha persistido hasta nuestros días.

En cuanto a las dificultades del "método corriente de enseñanza", expuso como obstáculos las condiciones en las que un solo maestro tenía que enseñar, pues al tener más o menos veinte niños - todos en diverso estado de aprovechamiento- sucedía que mientras se ocupaba de unos, otros perdían el tiempo. Proponía que todos comenzaran juntos, pues el atraso de unos propiciaría el de todos. Concluido el silabario, pasarían al departamento de

\footnotetext{
65 "Informe de la Municipalidad de Guatemala", AGCA, leg. 1074, exp. 23067, ff. 45v-46.

${ }^{66}$ Morelos Torres utiliza el texto Nuevo método para la enseñanza primaria, publicado por el Congreso del Estado de Chiapas, edición que no incluye el año.
} 
lectura, donde se leería un pasaje de la primera fábula: "aunque la mona se vista de seda, mona se queda". Un solo niño leería el periodo o periodos que se le asignarán, mientras los otros lo seguirían en sus respectivos cuadernos para que, al momento de que se le pidiera a otro niño continuar la repetición, pudiera hacerlo con prontitud. Tomarían en esto de una hora a tres cuartos. "Concluido el tratado de lectura, se ejercitarán en leer libros uniformes una cuarta parte del tiempo; otro tanto en leer manuscritos, y lo demás en escribir sobre sus muestras respectivas" (citado en Torres, 2015: 61). Esto tenía conexión con otro aspecto: la repugnancia del niño en aprender. Se preguntaba Córdova cómo se podía mantener en la inacción a los niños tres horas por la mañana y otras tantas por la tarde en una edad en la que no pueden estar quietos y, sobre todo, con una enseñanza "tan árida que ponía de mal humor a los maestros" (Córdova, 1824: 6). Además, por no comprenderlos, se castigaba a los niños. A su entender, lo conveniente era que no se admitieran más de doce niños y, ya comenzado el curso, que no se recibiera ni uno más. Lo que no impediría que, concluida una clase con ese número, el preceptor comenzara con otro grupo en la siguiente hora. Creía, además, que el buen semblante del maestro también era importante para transmitir confianza en el niño y hacer más agradable el aprendizaje. En suma, el fraile reducía a tres las causas de que con el método vigente se consumieran años en aprender a leer y escribir: el irracional sistema de la ortografía, el mal método que se había seguido para enseñar y la repugnancia de los niños para aprender. Para corregirlas, sugería reformar el sistema, encontrar otro método y hacer agradable al niño el aprendizaje (Córdova, 1824: 4).

En cuanto al sistema de ortografía, proponía quitar la diferencia de figuras dadas a una misma letra. Por ejemplo, la A, a, a-mayúscula, minúscula y cursiva - tenía tres diferentes figuras, Córdova sugirió que hubiera una sola. En el caso de las dos o tres letras que tienen distinto nombre y figuras y una misma consonancia, como la G, J, X, "pues de la misma forma se pronuncian xicara que jicara que gicara, y así, suprimiendo la x como inútil, y quedando la j para la pronunciación fuerte, y la g para la suave, como en gusto, quedará simplificado el sistema en esta parte" (Córdova, 1824: 4).

Otro punto digno de reforma era que todas las letras no tuviesen "constantemente un sonido idéntico siempre que se pronuncian", como con la c y la g. Sugería que el sonido blando de la c y la g fuera igual en todas las vocales, escribiendo y pronunciando, por ejemplo, cerella, cinto, en lugar de querella y quinto, gerra y gisante, en lugar de guerra y guisante. También apuntaba eliminar el deletreo, ya que, como se enseñaba, el niño debía pronunciar el nombre de cada letra de una sílaba antes de pronunciar la misma. Para fray Matías esto causaba gran confusión en los niños:

debiendo expresar en el deletreo los nombres de las consonantes compuestos de varias letras que no deben pronunciarse y que tal vez ninguna tiene el sonido que ha 
de tener la sílaba. En la palabra xabón ¿qué sonido empleamos al pronunciar equis que tenga alguna semejanza con la jota? Es cosa sensible ver las angustias de un niño cuando en el detestable deletreo pronuncia equis ege efe, sin atinar que toda esta baraunda quiere decir xefe (Córdova, 1824: 5)

Proponía que se diera a las consonantes su sonido neto, hallándose precedidas de una vocal, "teniendo el artículo la y el nombre genérico letra, que finalizan con a, se pueden nombrar lab, lad, laf, etc., o también letrag, letram, letrar, etcétera, porque en semejante caso conocerán los niños que el artículo la, y el nombre letra no son unos sonidos conexos con la pronunciación de los caracteres" (Córdova, 1824: 6; Tanck, 1990: 144). De esa manera, argumentó, se eliminaría el deletreo. ${ }^{67}$

A continuación, reflexionaba sobre la necesidad de que las imprentas imprimieran libros en los que se tomaran en cuenta sus recomendaciones: "Las imprentas no permiten identidad de figuras entre mayúsculas y minúsculas, y estando los libros escritos en el sistema corriente, serían inútiles para los que no hubiesen aprendido según él; de manera que, adoptar cualquier otro, es perder el tiempo, aunque éste se suponga de dos meses" (Córdova, 1824: 7). Opinaba que ningún gasto sería demasiado para formar una imprenta que editara conforme al sistema propuesto por él, "para que el común del pueblo se instruyera" (Córdova, 1824: 7).

En la sección "Advertencia a los maestros" (Córdova, 1824: 8), comienza su propuesta nueva de enseñanza: no debía ser con libros, sino con base en unos cartoncitos iguales en los que se escribieran todas las letras minúsculas en cursivas, una letra en cada cartón. Se harían dos juegos iguales y se les pondría una señal en la parte superior para que no se confundieran letras como n o p. Los cartones se colocarían frente al grupo y los chicos tendrían una pizarra cada uno o piedras lisas de mollejón o ladrillos bien raspados, además de barritas de yeso. En las pizarras se dibujarían rayas horizontales y verticales para las letras inclinadas (Córdova, 1824: 8). El maestro debería indicar una vocal, pronunciarla y después cada alumno repetirla. Enseguida, el maestro pediría a un niño que tomara una " $a$ " de los cartoncitos que había puesto en desorden. En caso de equivocarse, le haría notar el error y pediría a otro que "la busque hasta que la halle". Finalmente, aprendida la letra por el sonido y la forma, los niños tenían que formarla en su pizarra (Córdova, 1824: 9).

Una vez logrado lo anterior con las vocales, se pasaría a las consonantes. Como señala el nuevo método: "En las consonantes debe el maestro hacer bien perceptible su sonido, anteponiéndoles las voces letra, una, o la, como la letra b, en b; una f en f; o la s en s. Tal vez, dirán los niños ab, af, as, etcétera, en lugar de b, f, s, etcétera, pero éste no es error substan-

\footnotetext{
${ }^{67}$ De acuerdo con Dorothy Tanck, apoyada en un artículo de Gregorio Torres Quintero, de 1960, existe un librito de 1828 intitulado Razón del método del Dr. Córdova y Reglamento minucioso de las observaciones y conducta que observarán los maestros en él, pero hasta ahora no he podido localizarlo físicamente.
} 
cial, aunque será bueno corregirlo" (Córdova, 1824: 9). Una vez conocidas suficientes letras, podrían los niños pasar a la siguiente etapa, que consistiría en trabajar en la "Cartilla", tercera parte del Método, haciendo combinaciones, "hasta que no yerren" (Córdova, 1824:10). La "Cartilla" tiene la siguiente secuencia: a, e, b, i, o, u, c, d, r, f, g, j, l, m, n, p, s, t, z. En cada caso se iban haciendo combinaciones, primero simples, como ae, hasta las más complicadas, como zapato, orozuz e incluso, oraciones: los ziudadanos son felices por la paz, y esta no la ai sin obediencia, i observancia (Córdova, 1824: 10-13). El maestro se encargaría de dictar las letras y después las combinaciones para que los alumnos las escribieran, sin ver la cartilla. Como se dijo, el maestro tenía recomendado dar lecciones de una hora por la mañana y otra por la tarde. En el intermedio, los alumnos podrían seguir repasando lo aprehendido y señalaba que:

conocida la última letra y sabiéndola formar, debe considerarse concluida la enseñanza de leer y escribir; más que se perfeccionen los niños con el ejercicio, es preciso que estudien, si puede ser, hasta tomar de memoria, el tratado de ortografía, explicándoles primero el maestro así la doctrina de él, como los términos cuya significación no sepan (Córdova, 1824: 10).

El tratado tiene reglas de pronunciación, puntuación y tono para la lectura, por ejemplo, sobre la puntuación indica: "Después de figurarse con las letras la pronunziazión de las palabras, todabía ai necesidad de saberse, en cual de sus bocales se ade hazer el azento. ¿Ce maior o menor pausa se ade azer en la lectura, i con [e]ce tono debe pronunciarse el periodo?" (Córdova, 1824: 20). ${ }^{68}$ Así, sucesivamente, Córdova iba indicando cada aspecto de esa ortografía.

Otro apartado es la exposición de las reglas para leer en el sistema antiguo, en él, primero había que saber que las letras mayúsculas tienen diversa figura a las minúsculas, o corrientes y se muestra cuáles eran

Aa, Bb, Dd, Ee, Ff, Gg, LI, Mm, Nn, Rr, Tt

Se agrega que estas once letras tienen en su forma manuscrita casi la misma figura que en la impresa (Córdova, 1824: 14-15). También se explican las diversas características de pronunciación en ciertas combinaciones de letras, por ejemplo, los casos de la c y la g, que no tienen un sonido constante, cuando la c precede a la e, i, a, la i suena como z: "de suerte ce que escriben Cecilia, i pronunzian Zezilia. Téngase pues presente que la sílaba ce ciere decir, ze i la silaba ci ciere decir zi" (Córdova, 1824: 14). Finalmente, se presentan las letras que se habían eliminado: h, g, v, x, y. Hasta aquí el Método de Matías de Córdova para enseñar a leer y escribir a los niños de Guatemala y de Chiapas.

\footnotetext{
${ }^{68}$ El último apartado sobre la ortografía está en las pp. 15-23.
} 
Acerca de la aplicación del Método y sus resultados, no hay todavía un acuerdo y quizá habría que investigar más. Por una parte, es indudable que fue un esfuerzo muy importante de fray Matías de Córdova, que fue y ha sido ampliamente reconocido. Dorothy Tanck afirma que las noticias sobre el método llegaron hasta la ciudad de México, prueba de ello es que, una vez fundada la Academia de Primera Enseñanza en la capital del país, en febrero de 1827, los socios "publicaron un folleto sobre el estado de la educación y elogiaron el método del chiapaneco. $[Y]$ recomendaban a los mexicanos que no se engañaran por técnicas importadas: y sin ocurrir a tierras lejanas puede ser que en nuestro país encontremos arbitrios que satisfagan los deseos de la Academia". Recuérdese que hacia esos años se había adoptado el método lancasteriano de enseñanza mutua. El Método, pues, sorprendía y "por testigos presenciales" sabemos que éste y la propuesta en general de Córdova se consideraron "verdaderamente maravillosos" (Tanck, 1990: 146).

La publicación de su libro Razón del método... y reglamento minucioso quizá contribuyó a la divulgación de su Método, pese a la muerte de Córdova. No obstante, otro dominico, fray Víctor María Flores fue quien, poco después del fallecimiento de fray Matías, emitió quizá el juicio más severo acerca de la obra tantas veces mencionada, pues si bien elogió sus cualidades, también señaló que sólo servía para los mestizos que vivían en Ciudad Real, pero no para las comunidades indígenas del interior del estado. Debido a ello, este otro fraile escribió, con base en el método de Córdova, el suyo propio: el Método doméstico (Tanck, 1990: 147; Torres, 2015: 67-78). En opinión de Morelos Torres, el poco éxito del método de Córdova y el de otros intentos de alfabetización de los indígenas durante la primera mitad del siglo XIX se debió a tres factores: las propias condiciones de la provincia, la reticencia de los padres a enviar a sus hijos a la escuela y el estado de embriaguez de muchos de ellos (Torres, 2015: 20). Esto no disminuye en nada el gran reconocimiento que existe hacia el método fonético y la obra en pro de la instrucción pública del fraile dominico (Torres, 2015: 65-66).

\section{Las fábulas}

Otra contribución de Matías de Córdova que se considera también una propuesta educativa fue la redacción de fábulas y cuentos que, al parecer, publicó en el periódico El Para-rayo de Ciudad Real, donde escribía bajo el seudónimo de El Espeziero (Pinto, 1956: 1; González, 1960: 153-154). Una de sus fábulas-poema, quizá la más famosa, es "La tentativa del León y el éxito de su empresa", divulgada después de la muerte del autor. Un extenso artículo fue publicado por el doctor Fences Redish, ${ }^{69}$ a principios del siglo Xx, en el Diario de Centroamérica, con el objeto de debatir su originalidad, debido a una serie de réplicas escritas a partir

${ }^{69}$ Dr. Fences Redish, es el pseudónimo del escritor guatemalteco Manuel Valladares Rubio (1869-1927), miembro del conservador clan Aycinena y enemigo de los regímenes liberales. 
El poema tuvo gran éxito no sólo entre los intelectuales y estudiosos del fraile, sino también en Guatemala, y éste es el punto que nos interesa resaltar, porque en las escuelas primarias guatemaltecas se convirtió en una lectura obligada, formaba parte de la enseñanza de una moral (Cancino, 1981: 10-11). ${ }^{73}$ Es un texto que retoma ideas que, para Cancino Casahonda, "se vienen trasmitiendo desde la India hasta Persia, pasando por la Grecia clásica hasta nuestras tierras americanas" (Cancino, 1981: 9-15).

Desde su punto de vista, no hay nada original en aquél, pero sí cambios en el desenlace de la historia, pues en ésta "el hombre deja de ser un ente vegetativo y se transforma en un ser generoso, que abre trampas y perdona la vida y respeta la dignidad del león" (Cancino, 1981: 10). Generosidad, perdón, clemencia, eran los valores morales que se pretendían transmitir con aquélla a todos los individuos, fueran niños o adultos.

\section{A manera de conclusión}

Fray Matías de Córdova fue un hombre ilustrado y liberal que intentó, junto con otros hombres ilustrados de la época, incidir en la realidad que vivía. Buscó transitar hacia nuevos parámetros y directrices en varios ámbitos, siendo los más significativos el político y el educativo. En ambos aspectos hemos visto que, primero, junto con otros religiosos de su orden, luchó para conseguir que su provincia fuera independiente de la de Guatemala; después, con miembros de la élite ilustrada chiapaneca, impulsó la separación de Chiapas y su erección como estado independiente, y no pasó mucho tiempo para que decidieran su anexión a México.

Los afanes autonomistas se materializaron, desde el aspecto cultural y educativo, con la fundación de la Universidad Literaria, con la creación de la Sociedad de Amigos de Chiapas y con la promoción de la alfabetización tanto de los indígenas como de las castas. En este caso, fray Matías de Córdova contaba con su Método fácil para aprender a leer y escribir, que había concluido en 1824, cuando todavía Chiapas era parte de Guatemala y que se tomaría como el método para la enseñanza de las primeras letras en el nuevo estado. La contribución de Matías de Córdova a la instrucción pública no sólo quedó en el terreno de la alfabetización y castellanización, sino se extendió a una propuesta de formación moral, filosófica y religiosa. En esta tesitura, se incluye la redacción de sus fábulas, poemas, cuentos y otro tipo de escritos, de los que apenas atisbamos a uno de ellos.

En suma, los aportes del fraile dominico, tanto en el ámbito de la política como de la educación pública, respondieron a la confluencia de sus intereses como hombre ilustrado

\footnotetext{
${ }^{73}$ Se trata de una fábula-poema que ha recibido gran atención por los estudiosos de Córdova. Cancino criticó también la falta de interés mostrada por el poema del lado mexicano.
} 
y liberal, cruzados, además, por los afanes independentistas de él y otros individuos de la élite chiapaneca.

\section{Fuentes}

Archivos

AHDSC Archivo Histórico Diocesano de San Cristóbal de Las Casas, Chiapas.

AHCA Archivo Histórico de Centroamérica.

HBNG Hemeroteca de la Biblioteca Nacional de Guatemala.

ML Museo del Libro, Antigua, Guatemala.

Hemerografía

El Sol, Ciudad de México.

Diario de Centroamérica.

Bibliografía

Bonilla Bonilla, Adolfo (2005), "Matías de Córdova en el contexto del pensamiento económico y étnico ilustrado centroamericano", en Mercedes Olivera y María Dolores Palomo (coords.) (2005), Chiapas: de la independencia a la revolución, Ciesas/Consejo de Ciencia y Tecnología del Estado de Chiapas, México, pp. 215-229.

Cancino Casahonda, Enoch (1981), Fray Matías de Córdova, autor de la Independencia de Chiapas a los 160 años de su muerte: noticias acerca del hallazgo de sus restos, Gobierno del Estado de Chiapas, Tuxtla Gutiérrez.

Camacho Chacón, Ana Karla (2018), "Escuelas, misiones culturales, bibliotecas. La educación rural federal en tres municipios de Chiapas, 1928", Posgrado en Historia, México.

Contreras García, Irma (2001), Las etnias del estado de Chiapas. Castellanización y bibliografías, UnAM, México.

Córdova, Matías de, O.P. (1999), La tentativa del león y el éxito de su empresa, Consejo Estatal para la Cultura y las Artes de Chiapas, Tuxtla Gutiérrez.

Córdova, Matías de, O.P. (1998), Producción inédita de Fray Matías de Córdova, Unicach/Gobierno Constitucional del Estado, Tuxtla Gutiérrez.

Córdova, Matías de, O.P. (1932), Utilidades de que todos los indios y ladinos se vistan y calcen a la española, y medios de conseguirlo sin violencia, coacción ni mandato. Memoria premiada por la Real Sociedad Económica de Guatemala en 13 de diciembre de 1797, Imprenta de Ignacio Beteta, Nueva Guatemala, pp. 249-254.

Córdova, Matías de, O.P. (1824), Método fácil de enseñar a leer y escribir. Lo dispuso Fr. Matías de Córdova con el objeto de que se generalice la enseñanza primaria, Imprenta nueva de Juan José Arévalo, Guatemala, 23 pp.

Corzo, Ángel M. (1946), Fray Matías de Córdova, Gobierno del Estado de Chiapas, Departamento de Bibliotecas, Tuxtla Gutiérrez.

Díaz Laparra, Marco (1979), Eugenio María de Hostos y Fray Matías de Córdova: dos panoramas biográficos, Ministerio de Educación, s.l.

Diccionario Porrúa de historia, biografía y geografía de México (1995), t. 1, 6ª ed., Porrúa, México.

Fábregas Puig, Andrés (2011), "Fray Matías de Córdova y las raíces liberales del indigenismo mexicano", Anuario. Universidad de Ciencias y Artes de Chiapas, pp. 217-231. 
González Orellana, Carlos (1960), Historia de la educación en Guatemala, Costa Amic, México.

Guillén, Flavio (1932), Un fraile prócer y una fábula poema: estudio acerca de fray Matías de Córdova. Hizo este libro Flavio Guillén por encargo del General de División Jorge Ubico, presidente de la República de Guatemala, Tipografía Nacional, Guatemala.

Herrera Mena, Sajid Alfredo (2013), El ejercicio de gobernar. Del cabildo borbónico al ayuntamiento liberal. El Salvador colonial, 1750-1821, Universidad Jaume I, Castellón de la Plana.

Lira, Andrés (2007), "La historia como alegato para sobrevivir en la sociedad política: letrados y analfabetas en los pueblos de indios de la ciudad de México", Istor, vol. 29, pp. 26-46.

Lira, Andrés (1970), "Las escuelas de primeras letras en la municipalidad de Guatemala hacia 1824", Anuario de Estudios Latinoamericanos, vol. 3, pp. 117-140.

López Sánchez, Hermilo (1960), Apuntes históricos de San Cristóbal de las Casas, Chiapas, México, s. ed. México.

Meneses Morales, Ernesto (2001), Tendencias educativas oficiales en México, 1821-1911, Universidad Iberoamericana, México.

Olivera, Mercedes y María Dolores Palomo (coords.) (2007), Chiapas: de la independencia a la revolución, Ciesas/Consejo de Ciencia y Tecnología del Estado de Chiapas, México.

Pinto Gordillo, Mario (1956), Producción inédita de Fray Matías de Córdova, Círculo Literario Icachense/ Gobierno Constitucional del Estado, Tuxtla Gutiérrez.

Pérez de los Reyes, Marcos A. (1988), "Fray Matías de Córdova, su vida y su obra", en Beatriz de la Fuente (coord.), Memoria del IV Congreso de Historia del Derecho, t. 2, Instituto de Investigaciones Jurídicas, UnAM, México, pp. 857-870.

Recinos Aquino, Ivonne (2013), De la patria del criollo a la nación de las élites, Flacso, Guatemala.

Ríos Zúñiga, Rosalina (2015), "Secularización, centralización y configuración de un sistema de instrucción pública en México, primera mitad del siglo xIx (1812-1854)", en Joaquín Santana Vela y Pedro S. Urquijo Torres (coords.), Proyectos educativos de la colonia al México independiente, FFyL, Escuela Nacional de Estudios Superiores, Unidad Morelia, Morelia, pp. 267-289.

Ríos Zúñiga, Rosalina (2002a), "Contención del movimiento, prensa y asociaciones cívicas en Zacatecas", Historia Mexicana, núm. 205, pp. 103-161.

Ríos Zúñiga, Rosalina (2002b), La educación de la colonia a la república. El Colegio de San Luis Gonzaga y el Instituto Literario de Zacatecas, 1754-1854, CESU, UNAM/Ayuntamiento de Zacatecas, México.

Ríos Zúñiga, Rosalina (1998), "Educación y autonomía regional. Origen de los institutos literarios (18231832)", en Leticia Pérez Puente, De maestros y discípulos, siglos XVI al XIX, CESU, UNAM, México, pp. 193-233.

Ríos Zúñiga, Rosalina (1994), "De Cádiz a México. La cuestión de los institutos literarios (1823-1833)", Secuencia, núm. 30, pp. 5-31.

Rodríguez, Mario (1984), El experimento de Cádiz en Centroamérica, 1808-1826, Fondo de Cultura Económica, México.

Ruiz Abreu, Carlos Enrique (1999), Documentos coloniales para la historia de Chiapas: localización en el Archivo General de la Nación, Unicach/AGn, Tuxtla Gutiérrez.

Santiago Cruz, Francisco (1998), "Apuntes sobre la educación colonial en Chiapas", Boca de Polen. Revista Cultural, t. 2, núm. 3, pp. 38-43.

Shafer, Robert Jones (1958), The Economic Societies of the Spanish World (1763-1821), University of Syracuse, Syracuse, N.Y.

Tanck de Estrada, Dorothy (1999), Pueblos de indios y educación en el México colonial, 1750-1821, El Colegio de México, México.

Tanck de Estrada, Dorothy (1990), "Innovaciones en la enseñanza de la lectura en el México independiente, 1821-1840”, Nueva Revista de Filología Hispánica, vol. 38, núm. 1, pp. 141-160. 
Trens, Manuel Bartolomé (1957), Bosquejos históricos de San Cristóbal las Casas, Imprenta de la H. Cámara de Diputados, México.

Trens, Manuel Bartolomé (1942), Historia de Chiapas, pról. de Vicente Liévano Domínguez, s. ed., México.

Torres Aguilar, Morelos (2016), "Una normal y un método. La iniciativa de Matías de Córdova en Chiapas (1828)", Revista de Historia de la Educación Latinoamericana, vol. 18, núm. 26 (enero-junio), pp. $113-136$.

Torres Aguilar, Morelos (2015), Aproximaciones a la historia de la educación en Chiapas. Iniciativas de enseñanza en el siglo XIX, Universidad de Guanajuato/Universidad de Ciencias y Artes de Chiapas, Morelia.

Torres Aguilar, Morelos (2010), "La enseñanza de primeras letras en Chiapas en los albores de la independencia en un contexto iberoamericano", Revista Historia de la Educación Latinoamericana, vol. 14, pp. 139-168.

Vázquez Olivera, Mario (2005), "Chiapas, Centroamérica y México (1821-1824). Nuevos elementos sobre una antigua discusión", en Mercedes Olivera y María Dolores Palomo (coords.), Chiapas: de la independencia a la revolución, CIESAS/Consejo de Ciencia y Tecnología del Estado de Chiapas, México.

Zebadúa, Emilio (2011), Breve historia de Chiapas, $2^{a}$ ed., Colmex, Fideicomiso Historia de las Américas/ Fondo de Cultura Económica, México.

Recursos electrónicos

Martínez Mendoza, Sarelly (2018), "El nacimiento del periodismo chiapaneco", documento pdf disponible en: <http://redestudiosprensa.mx/hdp/files/107.pdf>; (fecha de consulta: 27/04/2018).

Rosalına Ríos ZúÑıGA es Doctora en Historia (Universidad de Pittsburgh, 2002), investigadora titular "B" del Instituto de Investigaciones sobre la Universidad y la Educación (IISUE) y profesora de la Facultad de Filosofía y Letras, ambos de la UNAM, además de miembro del Sistema Nacional de Investigadores (SNI). Sus principales líneas de investigación son historia de la educación e historia social y cultural de México en la primera mitad del siglo xIX. Ha publicado ocho libros como autora, coautora o coordinadora, entre los que destacan Formar ciudadanos: sociedad civil y movilización popular en Zacatecas, 1821-1853 (2005), unAm/Plaza y Valdés, México; en coautoría con Cristian Rosas Íñiguez, La reforma educativa de Manuel Baranda, documentos para su estudio, 1842-1846 (2011), UNAM, México; en colaboración con Juan Leyva (coords.), Voz popular, saberes no oficiales: humor, protesta, disidencia y organización desde la escuela, la calle y los márgenes (México, siglo XIX) (2015), unam/Bonilla Artigas, México, y con Mónica Hidalgo, Poderes y educación superior en el mundo hispánico. Siglos XV al xx (2016), IISUE, UNAM, México.

Recibido: 27 de abril de 2018

Aceptado: 8 de noviembre de 2018 